\title{
Development of Hydropriming Techniques for Sowing Seeds of Upland Rice in Uganda
}

\author{
Yoshihiro Nakao1, Godfrey Asea², Minoru Yoshino ${ }^{3}$, Nobuki Kojima ${ }^{3,4}$, Hiroyuki Hanada4, \\ Kisho Miyamoto ${ }^{4}$, Shin Yabuta ${ }^{5}$, Rieko Kamioka4, Jun-Ichi Sakagami5* \\ ${ }^{1}$ The United Graduate School of Agricultural Sciences Kagoshima University, Kagohsima, Japan \\ ${ }^{2}$ National Crops Resources Research Institute, Kampala, Uganda \\ ${ }^{3}$ Japan International Cooperation Agency, Tokyo, Japan \\ ${ }^{4}$ Appropriate Agriculture International Co. Ltd., Tokyo, Japan \\ ${ }^{5}$ Faculty of Agriculture Kagoshima University, Kagoshima, Japan \\ Email: nakao.yoshi.kagoshima@gmail.com, ^sakagami@agri.kagoshima-u.ac.jp
}

How to cite this paper: Nakao, Y., Asea, G., Yoshino, M., Kojima, N., Hanada, H., Miyamoto, K., Yabuta, S., Kamioka, R. and Sakagami, J. (2018) Development of Hydropriming Techniques for Sowing Seeds of Upland Rice in Uganda. American Journal of Plant Sciences, 9, 2170-2182. https://doi.org/10.4236/ajps.2018.911157

Received: September 3, 2018

Accepted: October 16, 2018

Published: October 19, 2018

Copyright (C) 2018 by authors and Scientific Research Publishing Inc. This work is licensed under the Creative Commons Attribution International License (CC BY 4.0).

http://creativecommons.org/licenses/by/4.0/

\begin{abstract}
Hydropriming is one of the presoaking, seed priming technique that allows seeds to imbibe water and go through the first stage of germination but does not allow radicle appearance. After water imbibition, seeds are dried to their original weight. This technique is used to help crops overcome environment stress. This study aims to assess the morphological traits of farmer's seeds for developing priming treatments so as to develop appropriate methods to maximize the effect of hydropriming. We collected farmer's samples of rice sowing seeds grown indifferent regions of Ugandan. For each sample, distribution of the seed density in percentages was calculated. Secondly, germination tests as per seed density levels and as per farmer's seed samples were conducted for deciding appropriate priming treatment. Finally, wooden boxes experiment was conducted to confirm priming effects. As the result, it was observed that the difference in seed density levels affects the quality of farmer's seeds, as observed in the case of NERICA4. If the radicle appears during soaking period, the newly developed radicle dies during the seed drying process in the hydropriming treatment. Seed germination was observed after $24 \mathrm{~h}$ of sowing at room temperature, even at a seed density level of 1.17, which is vigorous for germination. Consequently, farmer's seeds were soaked for $24 \mathrm{~h}$ to promote water absorption and activate metabolic pathways and to avoid germination failure when seeds are dried to their initial weight. After hydropriming treatment, plant growth was improved. Alternatively, significant difference was not observed in the mean emergence time between hydroprimed and unprimed seeds. These results suggest that priming the seeds by soaking for $24 \mathrm{~h}$ and drying to their initial weight considerably affects initial growth after emergence under dry soil condition.
\end{abstract}




\section{Keywords}

Rice, Priming, Germination, Emergence, Seed

\section{Introduction}

The importance of rice in Sub-Sahara Africa (SSA) has been increasing as both a food and cash crop. Recently, rice production has failed to meet demand and the influx of imported rice into domestic markets is increasing [1]. This leads to the deterioration of SSA economies. Therefore, establishing appropriate rice cultivation methods that can adapted to local environmental conditions is of paramount importance.

Rice is cultivated in four ecosystems of SSA: dryland (38\% of rice cultivated area), rain-fed wetland (33\%), deep-water and mangrove swamps (9\%), and irrigated wetland (20\%) [2]. Upland cultivated rice is often subjected to drought stress, even under normal rainfall conditions [3]. Poor stand establishment of dryland rice can be attributed to erratic rainfall and frequent droughts after seeding [4]. Crop stand establishment critically affects growth, development, and yield [5].

Hydropriming is one of the seed priming techniques. Khan [6] reported the terms "priming of seeds" which was coined by Malnassy in 1971. This technique is a pre-sowing treatment in which seeds are soaked in an osmotic solution that allows them to imbibe water and go through the first stage of germination, but does not allow the radicle to appear (protrude through the seed coat). After soaking, the seeds are dried to their original moisture content, after which they can be stored and later planted using conventional techniques [7]. Priming changes biochemical properties of the seeds, such as enzyme activity [8] [9] [10], and promotes the processes involved in germination, such as sugar mobilization [8] [9] [11]. This technique has been shown to increase germination percentage, shorten germination period and emergence time, improve initial growth, increase dry mutter weight, shorten growth period, increase yield, and improve kernel quality [7] [11] [12]. Elias and Soltani [13] have reported that hydropriming is more practical than osmotic and hormonal priming because of its low cost and beneficial effects as described in a meta-analysis article that focused on various methods of priming seeds of numerous crops. Thus, the use of hydropriming is believed to be economical in improving the initial growth of crops, particularly in developing countries.

Hydropriming has been introduced in SSA countries to overcome environmental stress, such as drought, in rice cultivation [14] [15]. Some hydropriming trials have been conducted by farmers [14]; however, many issues need to be addressed. In hydropriming treatment, seeds are soaked in water to allow them to imbibe water. They are then dried to their original seed weight. If a radicle appears during the soaking period, it dies during the seed drying process. There- 
fore, the time of germination and radicle appearance needs to be confirmed prior to hydropriming. The majority of farmers in Uganda use rice seeds that are harvested and conserved from the previous seasons for sowing [16] and the difference in the quality of these farmer's seeds vary [17]. This variation in seed quality may result in the difference in germination time. Hydropriming treatment might be difficult if there are differences in germination time between farmer's seeds. Thus, determination of the appropriate method for hydropriming of farmer's seeds is also difficult.

This study aimed to assess the characteristics of farmer's seeds, such as density and germination time, to develop an appropriate method for inducing maximal hydropriming effect.

\section{Materials and Methods}

We collected samples of rice sowing seeds (cultivar NERICA4 harvested in 2016) grown in two different regions of Uganda: western and northeast part of Uganda. Seed samples were divided into five groups of seed density by salt water separation method to separate seeds by specific gravities. This was performed using four batches of water, each with a different salinity. After separating seeds, they were washed with water and air dried at room temperature at the National Crops Resources Research Institute. Specific densities of the five defined seed quality categories were $1.00\left(1.00-1.08 \mathrm{~g} \cdot \mathrm{cm}^{-3}\right), 1.08\left(1.08-1.13 \mathrm{~g} \cdot \mathrm{cm}^{-3}\right), 1.13$ $\left(1.13-1.15 \mathrm{~g} \cdot \mathrm{cm}^{-3}\right), 1.15\left(1.15-1.17 \mathrm{~g} \cdot \mathrm{cm}^{-3}\right)$, and $1.17\left(>1.17 \mathrm{~g} \cdot \mathrm{cm}^{-3}\right)$. For each sample, we calculated distribution of the seed density in percentages. Every sample had a small number of empty grains, which floated on water; these were removed and not evaluated in the study.

We allowed the seeds to germinate in rolls of wet paper placed in zippered bags to maintain a constant level of humidity for the seeds at a mean temperature of $24.5^{\circ} \mathrm{C}$. Ten seeds were sown in triplicates. We measured the number of seeds that had germinated every $6 \mathrm{~h}$. Mean germination time was calculated using the following formula [18].

$$
\bar{t}=\sum_{i=1}^{k}\left(n_{i} t_{i}\right) / \sum_{i=1}^{k} n_{i}
$$

where $t_{i}$ : time from the start of the experiment to the $t^{\text {th }}$ observation (day or hour), $n_{i}$. number of seeds germinated in time $i$ (not the accumulated number, but the number correspondent to the $i^{\text {th }}$ observation), and $k$. the last time of germination [18].

Germination test as per seed density levels was conducted using sample No. 1, which had sufficient amount of farmer's sowing seeds. Germination test as per farmer's seed samples was conducted using the selected seeds of density $>1.17$. Sample No. 4 with large variation in seed quality was used for wooden boxes experiment in greenhouse (Table 1 ).

We primed seeds by soaking them in tap water at $25.1^{\circ} \mathrm{C}$ (average temperature) for an appropriate duration (determined by a pre-germination test) and then dried them for 3 days to attain initial seed weight. The effect of priming on 
germination was confirmed using the germination test as per seed density levels. The average moisture content of primed and control seeds used in the wooden boxes experiment was $13.2 \%$ and $14.1 \%$, respectively.

Wooden boxes experiment was conducted triplicates. For each experiment, we used wooden boxes (depth, width and height are each $1 \mathrm{~m}$ ) filled with soil gathered from a forest in Namlonge, Uganda $\left(0^{\circ} 30^{\prime} 46.1^{\prime \prime} \mathrm{N}, 32^{\circ} 38^{\prime} 03.3^{\prime \prime} \mathrm{E}\right)$. Each box was divided into two equal sections, one side for treated (primed) seeds, and the other side for control (non-treated) seeds. Three seeds were sown at 1-cm depth

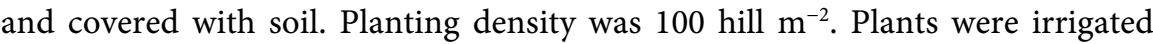
thrice per week at a volume of $18 \mathrm{~mm} \mathrm{~m}^{-2}$ week $^{-1}$. pF, the value obtained by calculating the common logarithm of the suction pressure, was measured using a tension-meter by inserting it $10 \mathrm{~cm}$ under the soil surface during the experimental period (Figure 1). Average of $\mathrm{pF}$ was 2.41. Emergence was observed 12 days after sowing. We determined the mean time for emergence in a manner similar to that used for calculating mean germination time. Factors such as establishment percentage, plant height, leaf area, and dry-matter weight of leaf blade and stem (leaf sheath + culm) were investigated at 13 and 23 days after sowing. The seedlings were dried at $80^{\circ} \mathrm{C}$ for 3 days using drying oven for measurement of dry matter weight. Plant establishment was defined as the plant growing well without withering and disease in this experiment. Leaf area was measured using LIA for Win32 ver0.376 $\beta 1$. Plant height uniformity was calculated as coefficient of variation (CV) between the plants that were observed. Analysis of variance followed by Tukey's test was conducted to evaluate farmer's seeds. t-test was conducted to compare priming and control. A p-value of $<0.05$ was considered significant.

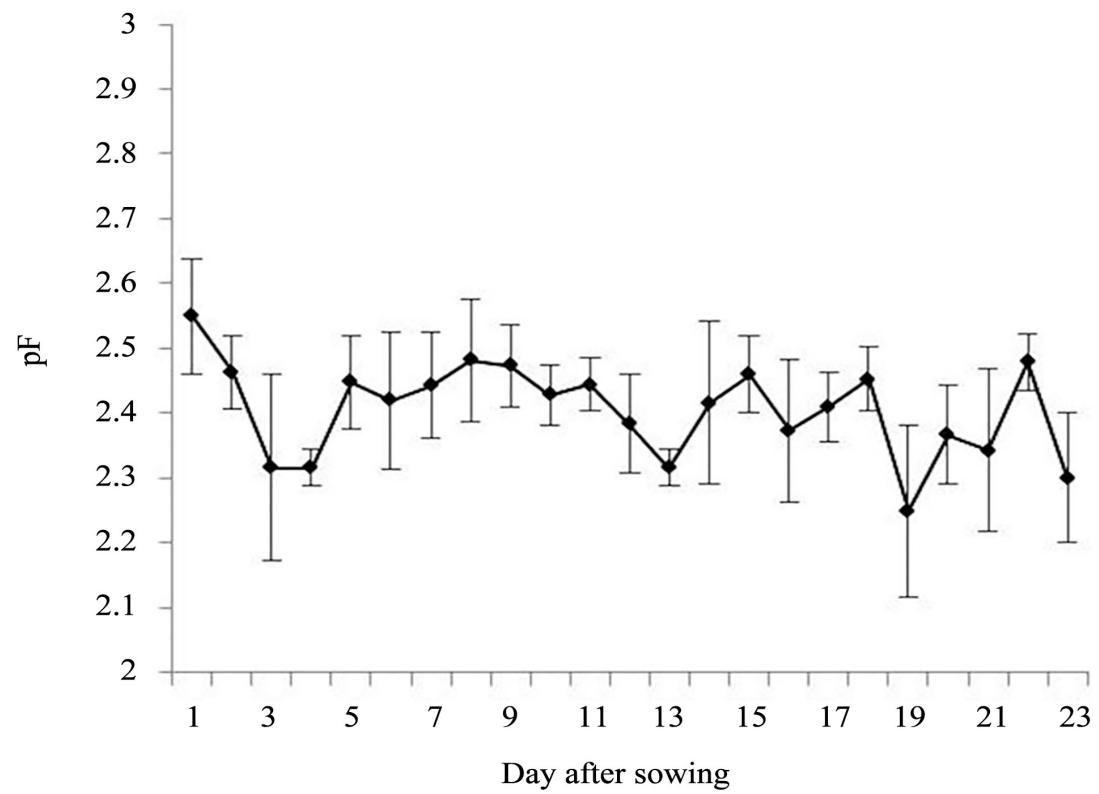

Figure 1. Change in soil $\mathrm{pF}$ during experiment in wooden box, Vertical bars indicate standard deviation $(\mathrm{n}=3)$ for soil $\mathrm{pF}$. 
Table 1. Distribution of farmer's seeds samples on the basis of seed density.

\begin{tabular}{cccccc}
\hline & \multicolumn{5}{c}{ Sample No. } \\
\cline { 2 - 6 } $\begin{array}{c}\text { Seed Density } \\
\left(\mathrm{g} \cdot \mathrm{cm}^{-3}\right)\end{array}$ & 1 & 2 & 3 & 4 & 5 \\
\cline { 2 - 6 } & 71.5 & 84.9 & 84.6 & 33.4 & 31.2 \\
\hline 1.17 & 8.8 & 4.9 & 2.3 & 15.1 & 22.8 \\
1.15 & 7.7 & 3.7 & 5.1 & 15.8 & 16.4 \\
1.13 & 6.8 & 4.3 & 4.3 & 20.8 & 12.5 \\
1.08 & 5.2 & 2.2 & 3.7 & 14.9 & 17.1 \\
1.00 & & & & & \\
\hline
\end{tabular}

\section{Results}

\subsection{Distribution of Seeds by Density}

The percentage of category of 1.17 seed density was $71.5,84.9,84.6,33.4$ and $31.2 \%$ at seeds sample 1, 2, 3, 4 and 5 respectively (Table 1). Category of 1.17 seed density was highest percentage with each famer's seed samples without exceptions. In sample No. 4, percentage of each seed density category was 33.4, $15.1,15.8,20.8$ and 14.9 at $1.17,1.15,1.13,1.08$ and 1.00 , respectively. In sample No. 5, percentage of each seed density category was $31.2 \%, 22.8 \%, 16.4 \%, 12.5 \%$ and $17.1 \%$ at $1.17,1.15,1.13,1.08$ and 1.00, respectively. Sample No. 4 and 5 are included for every levels of seed density equivalently. Without exception, most seeds belonged to the category of the greatest density (i.e., those with a seed density $>1.17$ ) (Table 1). Sample No. 4 and 5 were similar for every category of seed quality.

\subsection{Seed Germination}

Germination percentage of seeds in the category of 1.17 and 1.15 seed density was $>90 \%$ at $42 \mathrm{~h}$ after sowing (Figure 2). Analysis by ANOVA showed that significant difference was observed between seed densities. Germination percentages of all seed densities were $>70 \%$ at 72 days after sowing; however, significant difference was not observed between seed densities. First germination was observed at $30 \mathrm{~h}$ after sowing. Mean germination time was 38.8, 38.2, 38.8, 39.4, and $35.5 \mathrm{~h}$ for seed sample No. 1, 2, 3, 4, and 5, respectively. Significant difference was not observed between seeds samples obtained from different farmers with seed density of 1.17 (Figure 3). Mean germination time of primed seeds was $27.6,30.7,32.6,36.8$, and $42.1 \mathrm{~h}$ at density levels of $1.17,1.15,1.13,1.08$, and 1.00 , respectively (Figure 4). Therefore, $24 \mathrm{~h}$ soaking and drying to their original weight was defined as the hydro priming method available for NERICA4 to Ugandan farmers in this experiment. Mean germination time was shortened to $13,9.9,15.5,14.9$, and $5.6 \mathrm{~h}$ at density levels of $1.17,1.15,1.13,1.08$, and 1.00 by priming. Mean germination time of primed seeds is significantly shorter than that of control seeds as per seed density categories without exceptions $(\mathrm{p}<0.01$, 0.05). 


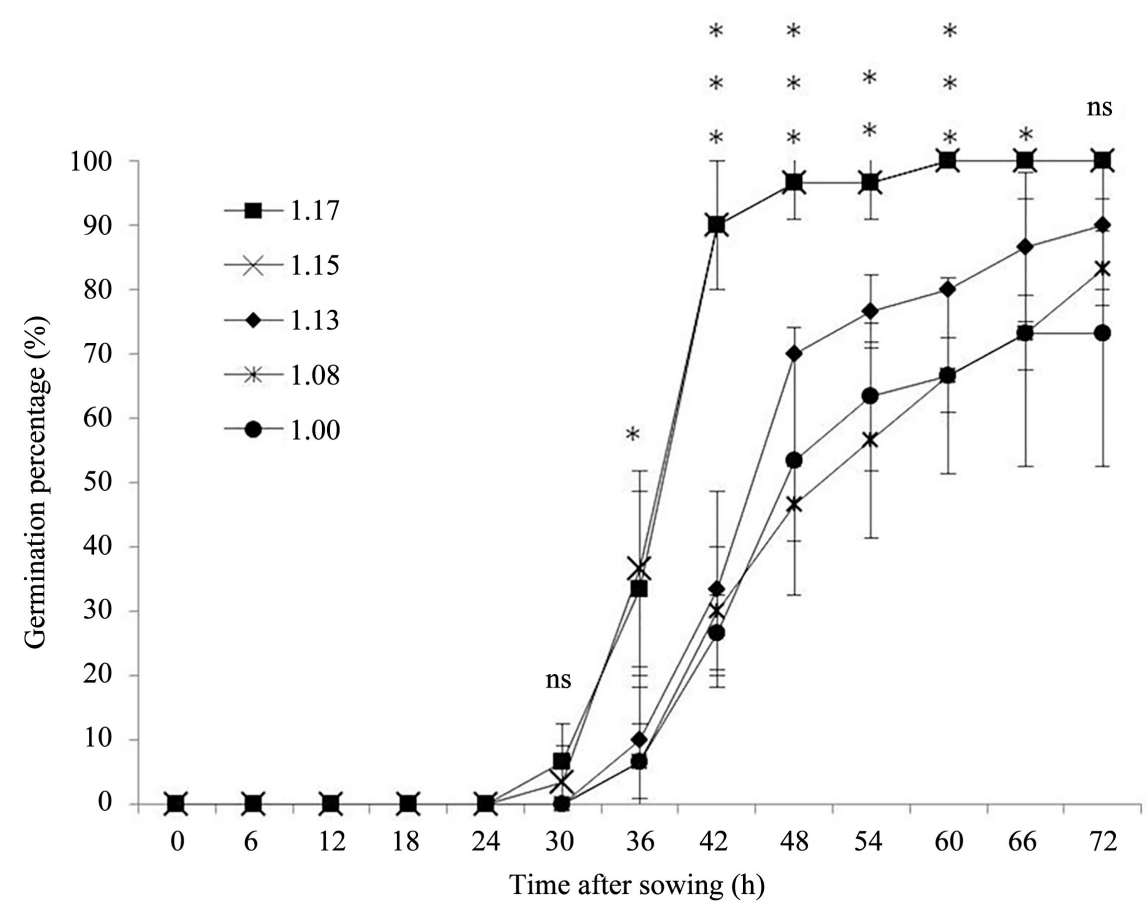

Figure 2. Transition of germination percentage for seeds of different densities, Vertical bars indicate standard deviation $(\mathrm{n}=3)$. Squares, crosses, diamonds, triangles, and round represent each seed density level. Bars indicate standard deviation $(n=3)$ for germination percentage. ${ }^{*},{ }^{* *}$ and, ${ }^{* * *}$ indicate significant difference $(\mathrm{p}<0.05, \mathrm{p}<0.01$, and $\mathrm{p}<0.001$, respectively) and " $n s$ " indicates no significant difference between seed quality levels as per ANOVA.

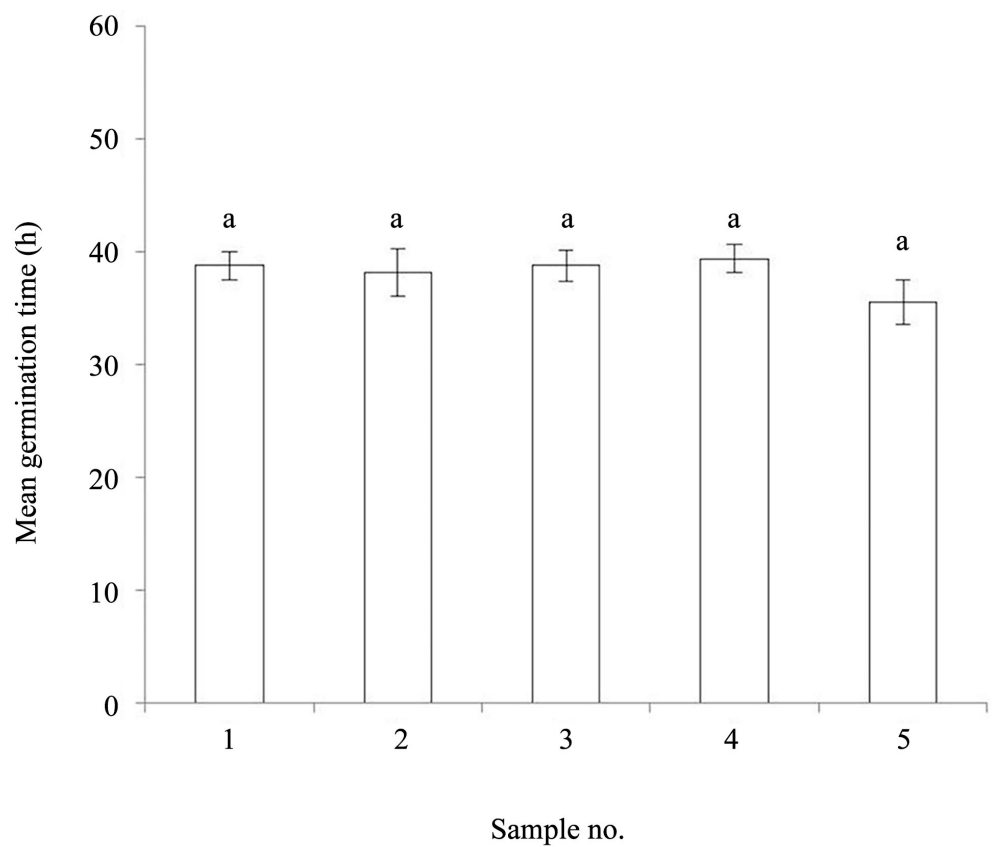

Figure 3. Seed germination of farmer's seeds samples. Vertical bars indicate standard deviation $(n=3)$. Bars indicate standard deviation $(n=3)$ for germination percentage. Seed with density 1.17 were used in this experiment. Same letters indicate non-significant differences between farmer's samples by Tukey's test. 


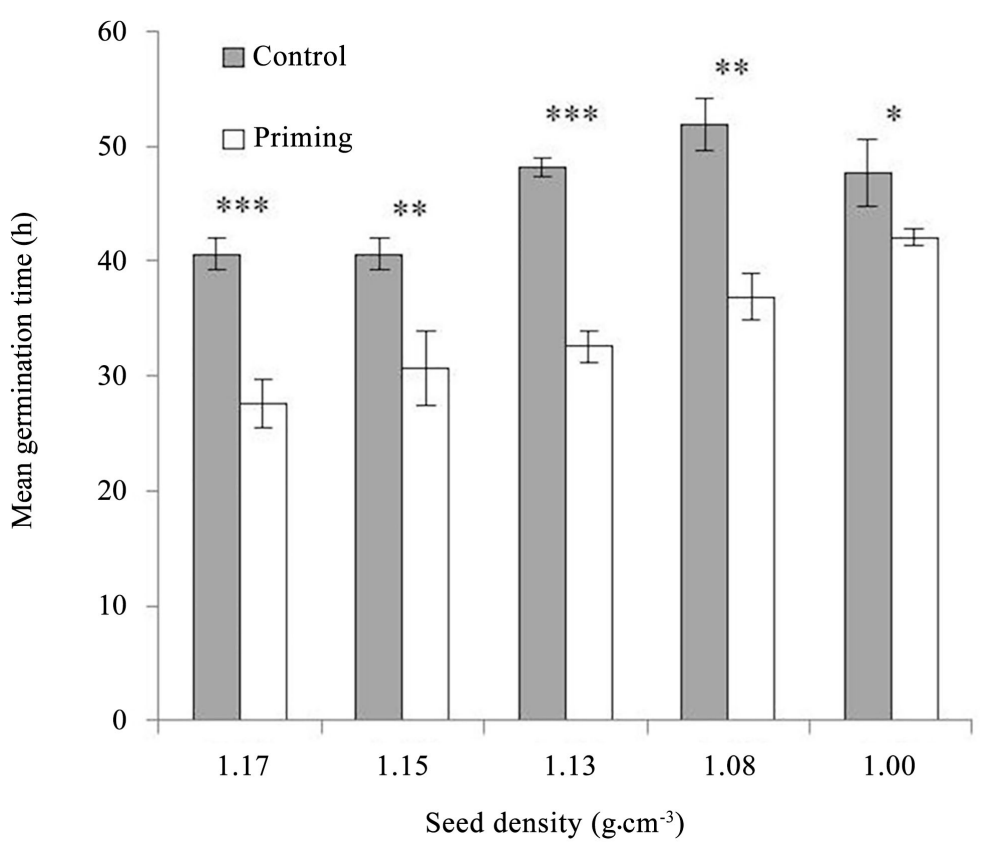

Figure 4. Seed germination of control and primed seeds. Seeds were allowed to imbibe in water and germination was monitored for $72 \mathrm{~h}$. Vertical bars indicate standard deviation $(\mathrm{n}=3){ }^{\star}{ }^{*}$ and ${ }^{\star *}$ indicate significant difference $(\mathrm{p}<0.05$ and $\mathrm{p}<0.01$, respectively) between control and priming by t-test.

\subsection{Wooden Boxes Experiment in Greenhouse}

Emergence was observed at 4 days after sowing in primed seeds and at 5 days after sowing in control seeds. Emergence percentage of the primed seeds was higher than those of control seeds throughout the experimental period and emergence percentage of the primed seeds was significantly higher than control seeds after 10 days from sowing. Emergence percentage of the primed and control seeds was $50.4 \%$ and $42.4 \%$ at 12 days after sowing (Figure 5). Mean emergence time of the primed and control seeds was 194.3 and $198.3 \mathrm{~h}$, respectively. Significant difference was not found between primed and control seeds (Figure 6). Establishment percentage, plant height, and dry-matter weight of plants obtained with primed seeds was greater than that of the control seeds; however, significant difference was not found at 13 days after sowing (Table 2). CV of plant height observed with the primed and control seeds were $12.0 \%$ and $26.9 \%$, respectively and significant difference was found between primed and control seeds at 13 days after sowing $(\mathrm{p}<0.05)$. Leaf area of primed and control seeds was $1.7 \mathrm{~cm}^{2}$ plant $^{-1}$ and $1.3 \mathrm{~cm}^{2}$ plant ${ }^{-1}$, respectively and significant difference was found at 13 days after sowing $(\mathrm{p}<0.05)$. Establishment percentage, plant height, and its $\mathrm{CV}$ of plants obtained with primed seeds were greater than that of control seeds; however, significant difference was not found at 26 days after sowing. Leaf area of plants obtained with primed and control seeds was $4.3 \mathrm{~cm}^{2}$ plant $^{-1}$ and $3.2 \mathrm{~cm}^{2}$ plant $^{-1}$, respectively and significant difference was found between primed seeds and control seeds after 13 days from sowing $(\mathrm{p}<0.05)$. Leaf dry and stemdry weight of plants obtained with primed seeds were signifi- 
cantly greater than that with control seeds and significant difference was found between primed and control seeds after 23 days from sowing (Table 2).

\section{Discussion}

\subsection{Appropriate Method of Hydropriming for Farmer's Seeds}

NERICA rice varieties have been reported to display good agronomic performance and resistance to Africa's harsh growth conditions, have particularly short growth duration, is much appreciated by farmers, and NERICA4 is grown in 35,000 ha land in Uganda [19].

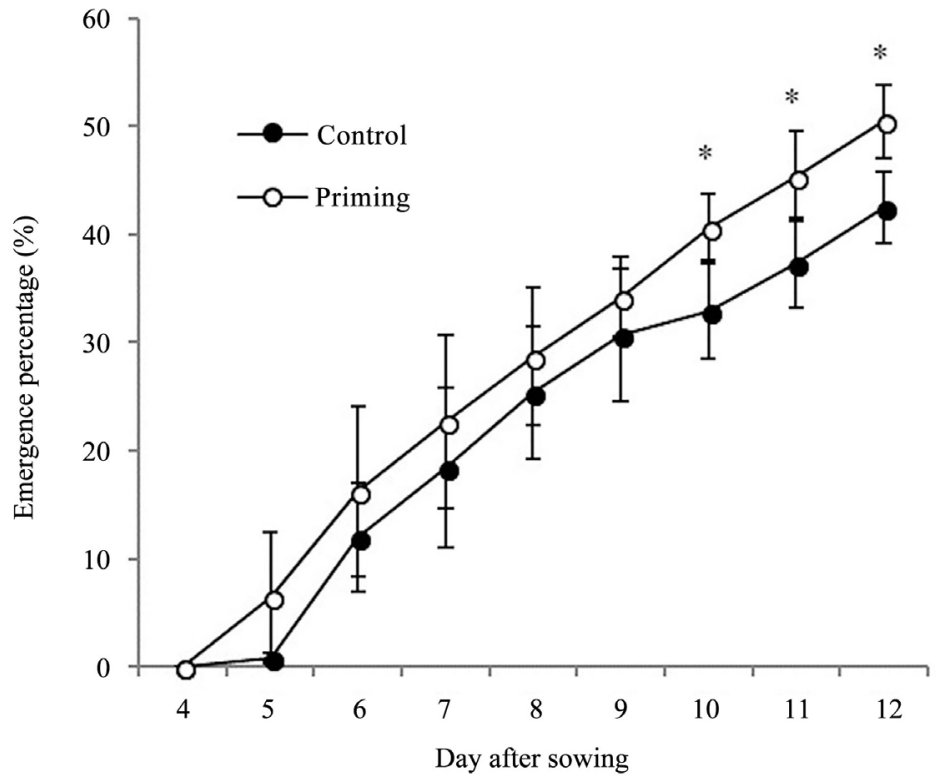

Figure 5. Transition of plant emergence percentage in wooden box. Vertical bar indicate standard deviation $(\mathrm{n}=3)$ for emergence percentage. ${ }^{*}$ indicate significant difference $(\mathrm{p}<$ $0.05)$ between control and primed seeds as per the results of t-test.

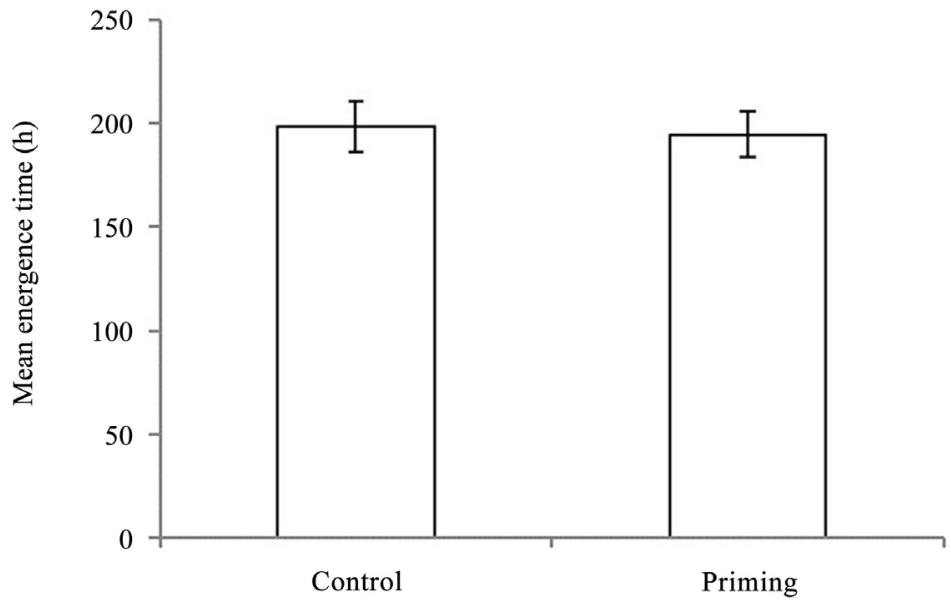

Figure 6. Plant emergence of control and primed seeds in wooden box experiment. Vertical bars indicate standard deviation $(n=3)$ for mean emergence time. There is not significant difference between control and primed seeds as per the results of t-test. 
Table 2. Effect of seed priming on seedling establishment, plant height, CV, leaf area, and dry-matter weight and result of t-test at 13 and 23 days from sowing in wooden box experiment.

\begin{tabular}{|c|c|c|c|c|c|c|c|}
\hline & & \multicolumn{6}{|c|}{ Days after sowing } \\
\hline & & \multicolumn{3}{|c|}{13} & \multicolumn{3}{|c|}{23} \\
\hline & & Control & Priming & t-test & Control & Priming & t-test \\
\hline Establishment (\% & & 35.8 & 42.2 & ns & 44.0 & 54.6 & ns \\
\hline Plant height $(\mathrm{cm}$ & & 9.2 & 9.8 & ns & 15.6 & 17.6 & ns \\
\hline $\mathrm{CV}(\%)$ & & 26.9 & 12.0 & * & 18.1 & 13.4 & ns \\
\hline Leaf area $\left(\mathrm{cm}^{2}\right.$ plan & & 1.3 & 1.6 & * & 3.2 & 4.3 & * \\
\hline SPAD & & - & - & - & 41.4 & 41.6 & ns \\
\hline \multirow[t]{2}{*}{$\begin{array}{l}\text { Dry matter weight } \\
\qquad\left(\mathrm{mg} \mathrm{plant}^{-1}\right)\end{array}$} & Leaf & 5.5 & 6.3 & ns & 13.6 & 19.0 & * \\
\hline & Stem & 4.4 & 4.5 & ns & 8.0 & 12.0 & $* *$ \\
\hline
\end{tabular}

* and $* *$ indicate significant difference $(\mathrm{p}<0.05$ and $\mathrm{p}<0.01$, respectively), and " $\mathrm{s}$ " indicates non-significant difference between control and priming by $\mathrm{t}$-test.

It is well known that differences in ripening ratio are affected by local environmental conditions and cultivation method. Characters of rice seeds cultivated at different localities were remarkably different [20]. We found some variation in seeds characteristics among seed samples collected from farms from two different regions in Uganda (Table 1). Our results show some farmer's samples include wide range of quality of seeds from poor to good. Higher seed density, 1.17 and 1.15, germination time shortened compared with lower seed density, 1.13, 1.08 and 1.00 (Figure 2). It is well known that specific gravity of seeds affects seed germination [21] and time of seedling emergence become earlier with increasing of seed weight [22]. This study also confirmed relationships between seed density and time for germination. There was no significant difference in the mean germination time among the farmer's seed samples we examined, but that low density category of seeds took significantly longer to germinate (Figure 2 and Figure 3). We also found that individual farms differed in overall seeds quality (determined by distribution of the five seed quality categories we examined). Thus, farms differ in their ratio of low to high quality seeds. Goto [17] expected that there might be a wide variation in the quality of farmer's seeds in Uganda. Our data confirmed the prediction and show that seeds from some farms we sampled varied widely in quality.

In the priming treatment, seeds are soaked in water, which allows them to imbibe water (but not long enough to stimulate radicle emergence); then the seeds are dried to their original moisture content. If radicle appears during soaking period, the newly developed radical becomes death in seed drying process. In this study, tested seeds could start germination after $24 \mathrm{~h}$ from sowing, even in 1.17 of density category seeds which is vigorous (Figure 2). Mean germination time of primed seeds was significantly shorter than that of control seeds by 
soaking of $24 \mathrm{~h}$ and drying (Figure 4). In consequence, this research suggests twenty four hours soaking is safety to avoid germination failure when dry back to initial weight in case of NERICA4. This technique appears to harden the seeds and significantly shortens the time needed for the seeds to germinate.

\subsection{Effects of Hydropriming on Emergence and Initial Growth}

We investigated the effects of priming seeds under dry soil conditions with average $\mathrm{pF}$ of 2.41. Soaking and then drying seeds increases $\alpha$-amylase activity [9] [11] [12] [23], which has been found to correlate with seed sugar content [9] [11] [23] and seedling dry weight. Farooq et al. [24] also found a correlation between soluble sugar content and seedling dry weight. It has been shown that increased $\alpha$-amylase activity hydrolyzes more starch and produces more soluble sugar, which helps promote vigorous seedling growth, faster plant growth, allometry, higher yields, and better kernel quality. We believe that increased $\alpha$-amylase activity (due to priming) was responsible for the differences we observed in germination, emergence, and seedling growth.

Seedling height uniformity of those grown from primed seeds was significantly better than that of those grown from control seeds (in the first 13 days only). Thus, improved uniformity is one effect of priming seeds. Farooq et al. [24] also have reported that primed seeds will better ensure uniform stand establishmentin directly seeded aerobic culture [24]. The more the irregulardisposition of plants, the greater the decrease in grain weight [25]. Our research confirms that seed priming improves uniformity in growth and so it might be possible that priming can also be used to improve grain yield.

In this research, significant difference was not found in mean emergence time of primed and control seed in wooden boxes experiment (Figure 6). Shoots elongation is inhibited, but root growth is stimulated at the time of seedling emergence with a decrease in soil moisture content [26] [27]. Seedling shoots in our study may have had difficulty in elongating at the time of seedling emergence, even though they had been primed. Optimum soil moisture range for seed priming is $8 \%-11 \%$ soil moisture content of sandy soil [7]. Our results show priming seeds cannot counteract stresses imposed by extremely dry soil conditions. However, plants from primed seeds grew better than those from control seeds after emergence (Table 2). Drainage after sowing accelerates root growth at the time of seedling emergence, but promotes shoot growth after seedling emergence [27]. Regardless of soil moisture condition, shoot growth in plants with primed seeds was greater than that in those obtained with control seeds [7]. This study suggested that primed seeds grow better than controls during the growth phase after emergence in soil dry condition. Seed priming profoundly influences the rapidity and percentage of seeds that germinate or emerge from the soil [13]. Effects of priming were generally evident on germination at first count, speed of seedling emergence, and seedling growth [28]. As above, previous studies argue that several priming effects were caused by quick germi- 
nation and emergence. On the other hand, there is an additional opinion by Matsushima [7], who showed that increased dry root weight was promoted by seed priming compared with that in the control with a decline in soil moisture content, but not promoted by accelerated germination. It suggests that plant growth caused not only quick germination and emergence but also other effects of priming. In our research, mean emergence time for primed seeds was not significantly different than for control seeds, but seedling growth after emergence was increased in primed seeds. Therefore, our results confirmed that plant growth caused not only quick germination and emergence but also other effects of priming concerning mean emergence time and seedling growth in dry soil condition. Furthermore, previous studies have confirmed a morphological priming effect only immediately after sowing [7] [10] [12]. Our research shows that seed priming leads to increased dry-matter weight not only immediately after sowing, but also at 26 days from sowing under dry soil condition.

\section{Conclusion}

Seeds used for growing rice vary in seed quality by field of origin (by farm) in Uganda in that some farms produce lower quality seeds than others. We found that seeds from Ugandan farms should be soaked for $24 \mathrm{~h}$ when hydropriming to promote water absorption and activate metabolic pathways. Soaking rice seeds for $24 \mathrm{~h}$ prevents germination failure for the NERICA4 seed varieties used in Uganda. This soaking regime will assure rapid growth, particularly after emergence. Priming effects begin immediately after sowing and last for at least 26 days, producing larger, heavier seedlings with larger leaf areas, characteristics that might improve survival and productivity.

\section{Conflicts of Interest}

The authors declare no conflicts of interest regarding the publication of this paper.

\section{References}

[1] Kiyoshi, S. (2008) Challenges for Rice Research and Extension in Sub-Sahara Africa: Cases from Tanzania and Ghana. JIRCAS Working Report No. 57, 161-168.

[2] Balasubramanian, V., Sie, M., Hijmans, R.J. and Otsuka, K. (2007) Increasing Rice Production in Sub-Saharan Africa: Challenges and Opportunities. Advances in Agronomy, 94, 55-133. https://doi.org/10.1016/S0065-2113(06)94002-4

[3] Hiroshi, N. (2008) Strategies of Upland Rice Breeding in Rain Fed Cultivation. JIRCAS Working Report No. 57, 55-63.

[4] Du, L.V. and Tuong, T.P. (2002) Enhancing the Performance of Dry-Seeded Rice: Effect of Seed Priming, Seeding Rate, and Time of Seeding. In: Pandey, S., Mortimer, M., Wade, L., Tuong, T.P., Lopez, K. and Hardy, B., Eds., Direct Seeding. Research Strategies and Opportunities, International Rice Research Institute, 241-256.

[5] Farooq, M., Siddique, K.H.M., Rehman, H., Aziz, T., Lee, D.J. and Wahid, A. (2011) Rice Direct Seeding: Experiences, Challenges and Opportunities. Soil \& Tillage Re- 
search, 111, 87-98. https://doi.org/10.1016/j.still.2010.10.008

[6] Khan, A.A. (1992) Preplant Physiological Seed Conditioning. Horticultural Reviews, 13, 131-181.

[7] Matsushima, K. and Sakagami, J. (2013) Effects of Seed Hydropriming on Germination and Seedling Vigor during Emergence of Rice under Different Soil Moisture Conditions. American Journal of Plant Sciences, 4, 1584-1593. https://doi.org/10.4236/ajps.2013.48191

[8] Soon, L.S., Kim, J.H., Hong, S.B., Kim, M.K. and Park, E.H. (1998) Optimum Water Potential, Temperature, and Duration for Priming of Rice Seeds. Korean Journal of Crop Science, 43, 1-5.

[9] Soon, L.S. and Kim, J.H. (2000) Total Sugars $\alpha$-Amylase Activity, and Germination after Priming of Normal and Aged Rice Seeds. Korean Journal of Crop Science, 45, 108-111.

[10] Hidetoshi, A. and Kobata, T. (2000) Dose Wetting and Redrying the Seed before Sowing Improve Rice Germination and Emergence under Low Soil moisture Condition? Plant Production Science, 3, 161-163. https://doi.org/10.1626/pps.3.161

[11] Muhammad, F., Barsa, S.M.A. and Wahid, A. (2006) Priming of Field-Sown Rice Seed Enhances Germination, Seedling Establishment, Allometry and Yield. Plant Growth Regulation, 49, 285-294. https://doi.org/10.1007/s10725-006-9138-y

[12] Hidetoshi, A. and Kobata, T. (2002) Effect of Seed Hardening on the Seedling Emergence and $\alpha$-Amylase Activity in the Grains of Wheat and Rice Sown in Dry Soil. Japanese Journal of Crop Science, 72, 220-205.

[13] Elias, S. and Soltani, A. (2015) Meta-Analysis of Seed Priming Effects on Seed Germination, Seedling Emergence and Crop Yield: Iranian Studies. International Journal of Plant Production, 9, 413-432.

[14] Harris, D., Pathan, A.K., Gothkar, P., Joshi, A., Chivasa, W. and Nyamudeza, P. (2001) On-Farm Seed Priming: Using Participatory Methods to Revive and Refine a Key Technology. Agricultural Systems, 69, 151-164. https://doi.org/10.1016/S0308-521X(01)00023-3

[15] Binang, W.B. and Shiyam, J. (2012) Effect of Seed Priming Method on Agronomic Performance and Cost Effectiveness of Rainfed Dry-Seeded NERICA Rice. Research Journal of Seed Science, 5, 136-143. https://doi.org/10.3923/rjss.2012.136.143

[16] Kisho, M., Maruyama, A., Haneishi, Y., Matsumoto, S., Tsuboi, T., Asea, G., Okello, S., Takagaki, M. and Kikuchi, M. (2012) NERICA Cultivation and Its Yield Determinants: The Case of Upland Rice Farmers in Namulonge, Central Uganda. Journal of Agriculture Science, 4, 120-135.

[17] Akio, G., Tsuboi, T., Asea, G., Haneishi, Y., Takagaki, M. and Kikuchi, M. (2013) An Assessment of Upland Rice Seed Quality in Uganda. Tropical Agriculture and Development, 57, 16-22.

[18] Ranal, M.A. and Santana, D.G. (2006) How and Why to Measure the Germination Process? Brazilian Journal of Botany, 29, 1-11. https://doi.org/10.1590/S0100-84042006000100002

[19] Diagne, A., Midingoyi, S.G., Woperei, M. and Akintayo, I. (2010) The NERICA Success Story: Development, Achievements and Lessons Learned. http://siteresources.worldbank.org/AFRICAEXT/Resources/258643-1271798012256 /NERICA-Success-Story-11-2010.pdf

[20] Takane, M., Futsuhara, Y. and Osone, K. (1956) Studies on the Characters of Seeds and Their After-Effects on the Next Germination of Rice Plants Cultivated at Dif- 
ferent Localities. Japanese Journal of Breeding, 5, 227-236.

https://doi.org/10.1270/jsbbs1951.5.227

[21] Zhichao, Z. and Takahashi, K. (1999) Some Factors Affecting the Emergence and Establishment of Rice Seedlings. Japanese Journal of Crop Science, 68, 379-384.

https://doi.org/10.1626/jcs.68.379

[22] Yutaka, U. (1975) Emergence and Organ Elongation of Seedling of Paddy Rice Sown under Upland Field Condition as Affected by Specific Gravity and Weight of Seed. Japanese Journal of Crop Science, 44, 414-418. https://doi.org/10.1626/jcs.44.414

[23] Muhammad, F., Barsa, S.M.A., Tabassum, R. and Afzal, I. (2006) Enhancing the Performance of Direct Seeded Fine Rice by Seed Priming. Plant Production Science, 9, 446-456. https://doi.org/10.1626/pps.9.446

[24] Muhammad, F., Wahid, A., Ahmad, N. and Asad, S.A. (2010) Comparative Efficacy of Surface Drying and Re-Drying Seed Priming in Rice: Changes in Emergence, Seedling Growth and Associated Metabolic Events. Paddy and Water Environment, 8, 15-22. https://doi.org/10.1007/s10333-009-0170-1

[25] Masami, H. and Izumi, S. (1965) The Effect of Irregular Disposition of Rice Plant on Yield in Direct Sowing Culture. Japanese Journal of Crop Science, 33, 399-402. https://doi.org/10.1626/jcs.33.399

[26] Manabu, T., Sato, T. and Maruyama, S. (2004) Growth Enhancement by Drainage During Seedling Establishment in Rice Direct-Sown into Puddled and Leveled Soil-Comparison with Seed Coating with Calcium Peroxide. Plant Production Science, 7, 324-328. https://doi.org/10.1626/pps.7.324

[27] Toru, S. and Maruyama, S. (2005) Seedling Growth and Dry-Matter Production under Drained Condition in Rice Direct-Sown into Puddle and Leveled Soil. Plant Production Science, 8, 209-215. https://doi.org/10.1626/pps.8.209

[28] Carvalho, B.M.L., Dias, D.C.F.S., Dias, L.A.S. and Araújo, E.F. (2005) Germination and Vigour of Primed Asparagus Seeds. Scientia Agricola, 62, 319-324. https://doi.org/10.1590/S0103-90162005000400003 